Revista de Antropología Social

ISSN: 1131-558X

http://dx.doi.org/10.5209/RASO.61852

\title{
Las bioeconomías de la provisión de óvulos en Estados Unidos y en España: una comparación de los mercados médicos y las implicaciones en la atención a las donantes ${ }^{1}$
}

Diane Tober ${ }^{2}$, Vincenzo Pavone ${ }^{3}$

Recibido: 29 de enero 2018 /Aceptado: 30 de julio 2018

Resumen. Los sistemas reguladores que controlan la reproducción con la participación de terceros determinan el modo en que las personas que donan materiales y trabajo reproductivos -óvulos, esperma y servicios de gestación subrogada- son escogidas y compensadas. Estados Unidos y España tienen regulaciones muy diferentes en lo que concierne a la reproducción con terceros, pero ambos son líderes mundiales en la prestación de tratamientos de fertilidad con donantes de óvulos. En este trabajo, analizamos el modo en que dos diferencias fundamentales entre estos sistemas -cómo son escogidas y cómo son compensadas las donantes- influyen en el mercado más amplio de los óvulos humanos, así como las implicaciones que esto tiene para las mujeres proveedoras. Apoyándonos en entrevistas y en el trabajo de campo realizado en Estados Unidos y en España, este artículo compara cómo la donación de óvulos compensada opera en un sistema público/privado regulado (España) frente al modo en que lo hace en un sistema médico no regulado de libre mercado (Estados Unidos). Exploramos cómo las diferentes bioeconomías reproductivas influyen en la mayor biodisponibilidad de unas mujeres sobre otras en el mercado de los óvulos humanos. Finalmente, hipotetizamos que los avances en las tecnologías de crioconservación de óvulos -y, por ende, el incremento del almacenamiento de óvulos en bancos- puede fomentar una cultura del consumo de los cuidados de la fertilidad en ambos países.

Palabras clave: Donación de óvulos; mercantilización del cuerpo; bioeconomías.

\section{[en] Bioeconomies of Egg Provision in the United States and Spain: Comparing Medical Markets and Implications for Donor Care}

\begin{abstract}
Regulatory systems governing third party reproduction determine how people providing reproductive materials and labor -including eggs, sperm, and gestational surrogacy services -are selected and compensated. The United States and Spain have very different regulations surrounding third party reproduction, but are both global leaders in providing fertility treatment with donor eggs. We examine how two key differences between these systems -how donors are selected and compensated-influence the broader market in human eggs and the implications for women who provide them. Drawing on interviews and fieldwork in the United States and Spain, this paper compares how compensated egg donation operates under a regulated public/private system (Spain) and the unregulated US free market medical system. Here we explore how different reproductive bioeconomies influence the bioavailability of some women over others in the human egg market. Finally, we posit that advances in egg freezing technologies -and the rise of egg banking- may further drive consumer culture fertility care in both locations.
\end{abstract}

Keywords: Egg donation; commodification of the body; bioeconomies.

Traducción de Clara Fernández de Bobadilla y Carlos Arca, revisada por Nancy Konvalinka.

2 Profesora asistente adjunta en la Universidad de California, San Francisco, Instituto para la Salud y el Envejecimiento.Diane.Tober@ucsf.edu

3 Investigador Titular en el Instituto de Políticas Públicas del Consejo Superior de Investigaciones Cientificas (CSIC).vincenzo.pavone@csic.es 
Sumario: 1. Introducción. 2. Biopolíticas y bioeconomías del mercado de los óvulos humanos. 3. Datos y metodología. 4. Regulaciones de la provisión de óvulos en Estados Unidos y en España. 5. Eggonomics en Estados Unidos y España. 5.1.- Libre mercado vs. compensación regulada de la donación. 5.2. La selección en el modelo de compensación escalonada vs. el modelo de compensación igualitaria. 5.3. Crioconservación, almacenamiento y el negocio cambiante de la provisión de óvulos. 6. Conclusión. 7. Referencias bibliográficas.

Cómo citar:Tober, D., Pavone, V. (2018). Las bioeconomías de la provisión de óvulos en Estados Unidos y en España: una comparación de los mercados médicos y las implicaciones en la atención a las donantes, en Revista de Antropología Social 27(1), 261-286.

\section{Introducción}

La expansión constante del mercado de óvulos humanos -y otros trabajos reproductivos de terceros- se puede atribuir a tres factores fundamentales: el aplazamiento de la maternidad (Konvalinka y Hernandez, 2012; Konvalinka, 2014; Basten et al., 2017), el incremento de las restricciones en la adopción internacional (Scherman et al., 2016) y el incremento del número de personas solteras y parejas homosexuales que acceden a los tratamientos de fertilidad (Perkins et al., 2016). Los especialistas en fertilidad recomiendan actualmente el uso de óvulos de donantes a mujeres cuyos ovarios han dejado de funcionar, así como a mujeres con trastornos genéticos (Lafuente, 2017).

De acuerdo con la Sociedad Americana de Medicina Reproductiva (ASRM en sus siglas en inglés): «El uso de la donación de óvulos como una terapia ante la infertilidad continúa aumentando cada año y en 2003, supuso un $12 \%$ de todos los ciclos de reproducción asistida» (ASRM, 2007). En Estados Unidos, entre los años 2000 y 2010, el uso de óvulos donados para ciclos de reproducción asistida casi se duplicó, pasando de 10.801 en el año 2000 a 18.306 en 2010 (Kawass et al., 2013). En 2015, el número total de ciclos de reproducción asistida con óvulos de donantes declarado alcanzó la cifra de 18.482, incluido el uso de embriones creados a partir de óvulos tanto congelados como frescos (CDC, 2015: 52). En España, de acuerdo con la Sociedad Española de Fertilidad (SEF, 2015), en torno a un 30\% de todos los tratamientos de fecundación in vitro (FIV) se realizan con donación de óvulos. Desde una perspectiva comercial, solo en 2013, la industria de la fertilidad en España generó \$670.000.000 dólares estadounidenses (López Gálvez y Moreno García, 2015). En Estados Unidos, para el año 2015, con 18.482 ciclos de óvulos donados, a un coste promedio de $\$ 25.000$ por ciclo, solo la demanda de óvulos generó unos ingresos de $\$ 462.050 .000$. Las empresas de inversión y los analistas de renta variable estiman que el mercado de la industria de la fertilidad en Estados Unidos estaba valorado, aproximadamente, en tres-cuatro billones de dólares en ingresos en 2015, y se prevé que crecerá aproximadamente un cuatro por ciento anual durante los próximos años ${ }^{4}$. Las tecnologías de crioconservación de óvulos mejoran aún más el potencial del beneficio clínico, ya que un número cada vez mayor de mujeres profesionales - particularmente en Estados Unidos- optan por congelar sus propios óvulos en un intento de preservar la fertilidad y retrasar la maternidad.

4 https://www.harriswilliams.com/sites/default/files/content/fertility_industry_overview_-_2015.05.19_v10.pdf. 
A medida que el mercado global de los tratamientos de la fertilidad mediante terceros continúa expandiéndose (Macklon, 2018) -y con ello la demanda de óvulos humanos (Waldby, 2015)-, emergen algunos países, en particular, como proveedores líderes en el mercado internacional de la fertilidad. Estados Unidos y España destacan como los principales destinos para el tratamiento de la fertilidad con óvulos de donantes si bien con estructuras reguladoras muy diferentes (Schurr, 2018). En tanto que la demanda de óvulos humanos aumenta en ambos países y las clínicas y otros negocios de fertilidad se enfrentan a la «escasez de óvulos» (Kawass et al., 2013; SEF, 2015, Marre et al., 2017), las mujeres jóvenes se ven cada vez más solicitadas para donar, normalmente, a cambio de una remuneración económica (Waldby, 2015). Algunos países prohíben remunerar a las donantes y solo permiten reembolsar el viaje, el sueldo no percibido y otros gastos directamente derivados de la donación. Algunas mujeres donan óvulos a familiares o amigos sin compensación alguna. Las entrevistas con proveedoras de óvulos indican que la mayoría tienen razones muy complejas para proporcionar óvulos, incluyendo razones monetarias y personales.

Este artículo compara la transacción de óvulos en dos contextos donde la compensación de la donación está permitida, en base a entrevistas con proveedoras remuneradas de óvulos y profesionales que intervienen en el proceso. Aquí, emplearemos el término «proveedora de óvulos» en vez de donante de óvulos con el objetivo de cuestionar el lenguaje de la donación altruista (Nahman, 2008; Baylis, 2014; Beeson, et al., 2015). Más específicamente examinamos: quién es considerado como biodisponible en estos dos mercados tan diferentes; de qué forma la vida biológica es incorporada de manera novedosa en el régimen de acumulación capitalista, mercantilizando gametos, tejidos y órganos y convirtiendo a las personas en meros recambios (Waldby y Mitchell, 2006; Waldby, 2006; Cooper, 2008; Fox y Swazey, 2013; Franklin, 2013; Pavone y Goven, 2017); y cómo los nuevos avances en las tecnologías de congelación de óvulos dan lugar a nuevas presiones en los mercados de óvulos humanos, ya sean regulados o noregulados. Señalamos, además, cómo las demandas del mercado de óvulos tienen un mayor impacto en las mujeres que perciben bajos salarios, quienes casualmente poseen características socialmente deseables.

\section{Biopolíticas y bioeconomías del mercado de óvulos humanos}

Las proveedoras de óvulos se encuentran, habitualmente, en un rango de edad que va desde los 21 a los 35 años, aunque algunas solo tienen 18 años, y muy pocas proveedoras remuneradas lo hacen pasados los 28 años. Los óvulos de las mujeres más jóvenes, que se encuentran entre los 18 y los 25 años, producen tasas de éxito en el embarazo más altas que los de mujeres más mayores (Cohen et. al. 1998), lo que genera una mayor demanda de mujeres jóvenes. En un ciclo de donación de óvulos, las mujeres se inyectan hormonas sintéticas para permitir que un mayor número de folículos lleguen a la madurez durante un periodo que va, normalmente, de dos a tres semanas. Según un informe del Instituto de Medicina (IOM, en sus siglas en inglés) sobre directrices de la donación de óvulos para la investigación con células madre, 10-15 folículos maduros se considera el número «seguro» para un solo ciclo de donación en interés a proteger la salud de la donante y reducir el riesgo del síndrome de hiperestimulación ovárica (SHO) -una complicación potencialmente mortal (IOM, 2006; Guidice et al., 2007; Balen, 2008)-. Ciertamente, el proceso supone riesgos para la donante, especialmente 
cuando se producen grandes cantidades de óvulos (Beeson y Lippmann, 2006). Sin embargo, las investigaciones sobre los efectos de la ovulación inducida y la extracción de óvulos en las mujeres proveedoras son escasas y solo actualmente este campo de investigación se empieza a consolidar (Klein y Sauer, 2012).

En el mercado global de órganos humanos (Cohen, 2001; Scheper-Hughes, 2003, 2007) y úteros gestacionales (Deomampo, 2016), los cuerpos pobres, marginalizados y, a menudo, de piel «oscura» del mundo son los principales proveedores. Cuando se trata, sin embargo, de óvulos humanos, si bien la necesidad financiera es la principal motivación en la decisión de las mujeres para proveer óvulos de forma remunerada, estas mujeres poseen, además, características a las que se atribuye valor genético tales como la piel clara, los ojos azules y la educación universitaria (Martin, 2018). Por tanto, el peso de la biodisponibilidad se carga sobre aquellos que son «privilegiados biológicamente» pero con problemas económicos. Los mercados de óvulos humanos y sus contextos regulatorios revelan las intersecciones entre las biotecnologías y las bioeconomías reproductivas emergentes (Pavone y Goven, 2017). Aquí, hacemos referencia a la «bioeconomía» en términos de cómo «las economías globales se basan en la manipulación biotecnológica» de gametos y cuerpos (Pavone y Goven, 2017: 9) y cómo los proveedores de material genético se entrecruzan con mercados médicos, instituciones y políticas más amplias. Mediante las prácticas de aprovisionamiento de óvulos, exploramos cómo las bioeconomías capitalizan la desigualdad (Lafuente, 2017; Namberger, 2017). Además, estos mercados convierten a los proveedores de servicios y productos corporales en una fuerza laboral reproductiva que combina «altruismo» e ingresos (Tober, 2002; Álvarez, 2008, 2010). El turismo reproductivo internacional, con terceros como proveedores, da lugar a un nuevo tipo de empleo temporal para migrantes, ya que algunas mujeres viajan cruzando fronteras para proveer de óvulos y úteros a cambio de diferentes grados de compensación (Chatterjee y Mondal, 2014; García y Hernández, 2015). Esto tiene implicaciones, no solo para las donantes sino también para las familias formadas mediante donación y para el parentesco transnacional (Sánchez, 2009; Jociles, 2016).

El comercio en expansión de la atención médica tiene implicaciones tanto para los países de origen como para los receptores (Whittaker et al., 2015). Esto es especialmente cierto en los viajes reproductivos, donde las mujeres de bajos ingresos son desproporcionadamente las proveedoras de servicios de subrogación y donación de óvulos (Ginsburg y Rapp, 1996; Whittaker y Speier, 2010; Nahman, 2011; Speier, 2016; Kroløkke, 2017). Como resultado, algunos académicos han criticado los viajes reproductivos de terceras partes proveedoras como una forma de trata de personas (García y Hernández, 2015; Chatterjee y Mondal, 2014), con consecuencias tanto para las proveedoras como para las familias creadas a través de donantes y el parentesco transnacional (Sánchez, 2009; Jociles, 2016).

En el mercado de los óvulos humanos, donde los rasgos se transmiten a los futuros niños, el peso de las aptitudes pasa a mujeres, mayormente jóvenes de piel clara (Lafuente, 2017), aunque puede haber variaciones individuales. Pese a que la dinámica de selección funciona de manera diferente según los contextos culturales, la demanda de proveedoras de óvulos rubias, con ojos claros y piel clara, además de educadas, refleja en parte los rasgos demográficos de los pacientes/clientes de fertilidad, que tienden a ser personas más adineradas, educadas y de piel más clara procedentes de todo el mundo (Keehn et al., 2015). Por otro lado, las gestantes subrogadas -como no aportan material genético- pueden ser cualquiera cuyo útero funcione. En este sentido, hay una jerarquía de diferentes capacidades reproductivas -así como 
una jerarquía económica dentro del mercado de óvulos- que está impregnada de connotaciones eugenésicas (Daniels y Heidt-Forsythe, 2012).

\section{Datos y metodología}

Los datos que se presentan en este artículo son el resultado de investigaciones independientes que han sido llevadas a cabo por ambos autores. Todos los nombres que se emplean son seudónimos. Con financiación inicial de una subvención de investigación individual de la Universidad de California, San Francisco (UCSF) ${ }^{5}$, Tober recogió 154 encuestas online y realizó 90 entrevistas abiertas a proveedoras de óvulos actuales, para algunas era su primera vez y otras lo habían hecho anteriormente. Las informantes fueron captadas mediante un grupo online internacional de actuales, anteriores y futuras proveedoras de óvulos, mediante agencias de donación de óvulos así como a través de ofrecimientos y el boca a boca. Se hicieron otras 20 entrevistas a endocrinos especializados en reproducción, fundadores y captadores de agencias, así como a consejeros genéticos y psicólogos que trabajan en la industria de la donación de óvulos en Estados Unidos. En 2015, Tober llevó a cabo otras entrevistas preliminares con profesionales de la fertilidad en España. Como parte del Proyecto Nacional de Investigación BIOARREME, el equipo de investigación liderado por Vincenzo Pavone realizó 20 entrevistas semi-estructuradas al personal médico y profesionales que trabajan en programas de provisión de óvulos en 11 clínicas privadas de diferentes tamaños en toda España. Las entrevistas se realizaron a ginecólogos, embriólogos, directores de marketing y directores de programas ${ }^{6}$. Haciendo uso de estos dos conjuntos de datos, en las siguientes secciones del artículo, comparamos cómo se organiza la provisión de óvulos como práctica, las interacciones médicas profesionales con las proveedoras de óvulos y los receptores, y los modelos comerciales/reguladores que impulsan esta bioeconomía altamente rentable.

\section{Regulaciones de la provisión de óvulos en Estados Unidos y en España}

Tanto Estados Unidos como España permiten la donación de óvulos con compensación económica, pero bajo diferentes condiciones. En España, la ley 14/2006 recoge tres restricciones principales a la donación de óvulos: 1) las donantes de gametos deben permanecer en el anonimato y solo se compartirá información general sobre la donante con los padres intencionales; 2) las donaciones deben ser «altruistas», lo que quiere decir que a las donantes solo se les ofrece una compensación económica por su esfuerzo, tiempo y gastos, que no excede los 1.100€; y 3) los médicos escogen a las donantes en nombre de sus pacientes, en principio, por razones basadas puramente en la información médica y en la coordinación fenotípica entre la donante y la mujer receptora, de forma que no son los padres intencionales quienes escogen a la donante.

\footnotetext{
La investigación en Estados Unidos se realizó a través de la Universidad de California, San Francisco (UCSF), y fue autorizada por el Comité de Etica para la investigación con sujetos humanos de la UCSF. Este proyecto fue financiado por un Individual Investigator Grant, de la Universidad de California, San Francisco. Nuestro especial agradecimiento a los auxiliares de investigación del proyecto: Joanna Lamstein, Rella Kautiainan y Allyn Benintendi.

${ }_{6}$ Las entrevistas fueron realizadas principalmente por Sara Lafuente, y los datos resultantes fueron analizados, tanto individualmente como por separado, por Sara Lafuente y Vincenzo Pavone.
} 
Actualmente, existen múltiples debates en torno a la ley española sobre el tratamiento que hace de la provisión de óvulos, esperma y gestación subrogada (no permitida en España) y de quién tiene acceso al tratamiento; debates destinados a generar un marco ético para evitar así la mercantilización de los óvulos y proteger la identidad de la donante.

Incluso con una compensación limitada, hay suficientes mujeres que se presentan para proporcionar óvulos por menos de 1.100€. Por un lado, limitar la compensación reduce el nivel de incentivo financiero; al mismo tiempo, sin embargo, la compensación limitada reduce el grado en que las proveedoras de óvulos en España pueden beneficiarse financieramente del biomercado reproductivo en comparación con sus homólogas estadounidenses. En Estados Unidos, la recomendación de la Sociedad Americana de Medicina Reproductiva (ASMR, en sus siglas en inglés) limitando la compensación a las proveedoras de óvulos a \$10.000 - como una protección ante el incentivo indebido- fue impugnada mediante una demanda colectiva como un intento de «fijar los precios» (Klitzman y Sauer, 2015). En un acuerdo extrajudicial, la ASMR retiró de su página web y de otros materiales informativos las directrices financieras sobre la remuneración a las donantes.

Tanto Estados Unidos como España permiten la compensación a las donantes de óvulos y lideran el mercado como los principales centros de provisión de los tratamientos de fertilidad con óvulos de donantes, lo mismo para los residentes del país como para los viajeros reproductivos. Es mucho más común que las personas que buscan un tratamiento de fertilidad viajen a los países de destino para obtener bienes y servicios reproductivos; sin embargo, en la investigación de Tober, de las 154 donantes de óvulos encuestadas, 29 habían venido de otros países a Estados Unidos para proporcionar óvulos al menos en una ocasión y también habían viajado a otros destinos, y una donante estadounidense lo había hecho a Tailandia para proporcionar óvulos a una pareja gay de España y su portadora gestacional (Tober y Kroløkke, de próxima aparición). Aunque no es un destino para proveedoras de óvulos extranjeras como Estados Unidos (Johnson 2017), las inmigrantes residentes en España de Europa del Este y de las antiguas colonias españolas, de hecho, constituyen una fuente frecuente de óvulos (Nahman, 2016; Lafuente, 2017) en un sistema donde «la donación altruista» significa que se les paga a las proveedoras un mínimo para sostener una industria próspera (Marre et al., 2017).

Los padres intencionales buscan tratamientos de fertilidad transfronterizos por múltiples razones, incluyendo la reducción de costes, la elusión de las leyes locales que restringen la reproducción mediante terceros o quién puede acceder a estos servicios y la percepción de una mayor calidad en el cuidado o una mayor eficacia (ASMR, 2013). España es el destino principal en Europa donde acuden padres intencionales, principalmente, de Reino Unido, Italia, Francia y Alemania (Nygren, Admason et al., 2010; SEF, 2015). Actualmente, más del 50\% de los tratamientos de fertilidad in vitro con donantes de óvulos en Europa se realizan en España (Shenfield et al., 2010; Pennings et al., 2014). En España, las parejas del mismo sexo y las personas solteras pueden recibir tratamiento de fertilidad con gametos de donantes, si bien no se permite la subrogación, ya que la persona que da a luz se considera la madre legal (González Pineda, 2015). Debido a esta política, los españoles que necesitan servicios de subrogación viajan al exterior, siendo Estados Unidos su principal destino.

En Estados Unidos, un destino líder para los padres intencionales de todo el mundo, no existe una política nacional uniforme que regule la donación de esperma y óvulos o la subrogación. La Sociedad Americana de Medicina Reproductiva (ASRM) tiene pautas, pero no son leyes vinculantes. Mientras que las guías de la ASRM recomiendan que las donantes de óvulos no pasen más de seis ciclos de donación de 
óvulos, muchas clínicas y agencias no siguen esto en la práctica, especialmente, cuando una donante puede ser llamada para someterse a un ciclo extra de modo que los padres intencionales puedan tener un hermano biológico completo para su hijo existente -lo que a menudo se conoce como un «proyecto de hermanos»-. Las proveedoras de gametos no están obligadas a permanecer en el anonimato y no existe una política en torno a las donaciones abiertas vs. las donaciones anónimas, lo que deja a los padres intencionales, clínicas, agencias y mujeres proveedoras de óvulos margen suficiente para negociar el contacto, aunque esto varía de una clínica a otra, y algunas requieren el anonimato. Como resultado de su reputación médica así como de sus regulaciones flexibles, Estados Unidos destaca como destino principal para la gestación subrogada. La tabla siguiente resume el panorama de la provisión de óvulos en los dos países:

Tabla 1. Comparación de los marcos legales, económicos y médicos para la donación de óvulos en EE.UU. y España ${ }^{7}$

\begin{tabular}{|c|c|c|}
\hline & Estados Unidos & España \\
\hline Semejanzas & \multicolumn{2}{|c|}{$\begin{array}{l}\text { - Se permite la compensación a la donante por el tiempo empleado, los gastos y } \\
\text { las molestias ocasionadas. } \\
\text {-Se capta con mayor frecuencia a mujeres más vulnerables económicamente. } \\
\text {-Son los principales destinos para los viajes reproductivos. }\end{array}$} \\
\hline \multirow[t]{4}{*}{ Diferencias } & $\begin{array}{l}\text { Los padres intencionales escogen } \\
\text { a las donantes a partir de perfiles, } \\
\text { buscando rasgos específicos. }\end{array}$ & $\begin{array}{l}\text { Los médicos escogen a la donante basándo- } \\
\text { se en similitudes fenotípicas que la donante } \\
\text { tiene con la madre intencional. }\end{array}$ \\
\hline & $\begin{array}{l}\text { Se puede negociar una donación } \\
\text { abierta o anónima, lo que impli- } \\
\text { ca que la donante puede en algún } \\
\text { momento conocer personalmente } \\
\text { a los padres intencionales y/o los } \\
\text { hijos genéticos. }\end{array}$ & El anonimato es obligatorio. \\
\hline & $\begin{array}{l}\text { El pago compensatorio a las do- } \\
\text { nantes va desde los } \$ 500 \text { hasta } \\
\text { los } \$ 250.000, \text { manteniéndose } \\
\text { una media de } \$ 5.500 \text { en el primer } \\
\text { ciclo* } \\
\text { Referencia: El salario mínimo } \\
\text { anual: } \$ 14.892^{* *}\end{array}$ & $\begin{array}{l}\text { El pago a las donantes se mueve entre los } \\
800 € \text { y los } 1.100 €,(\$ 900-\$ 1.200) \text {, acordados } \\
\text { a nivel nacional, con variaciones mínimas * } \\
\text { Referencia: el salario anual mínimo es de } \\
\$ 12.317 * *\end{array}$ \\
\hline & $\begin{array}{l}\text { La atención médica tras la dona- } \\
\text { ción es variable, normalmente ni } \\
\text { siquiera ofrecida por las clínicas. } \\
\text { Las donantes que sufren com- } \\
\text { plicaciones pueden recibir una } \\
\text { tarjeta especial de seguro médico } \\
\text { para acudir a emergencias. }\end{array}$ & $\begin{array}{l}\text { Los tratamientos médicos tras la donación se } \\
\text { encuentran disponibles mediante el sistema } \\
\text { público de salud o en la clínica en la que se } \\
\text { proporcionaron los óvulos. }\end{array}$ \\
\hline
\end{tabular}

*Información obtenida mediante el trabajo de campo. **Información de 2017, fuente: OECD https://stats.oecd.org/ Index.aspx?DataSetCode=RMW

7 Queremos agradecer a Nancy Konvalinka la elaboración de la versión original de esta tabla. 


\section{Eggonomics $^{8}$ en Estados Unidos y España}

\subsection{Libre mercado vs. compensación regulada de la donación}

Tal y como indica la tabla anterior, la compensación a las donantes varía enormemente entre los dos países. Hasta el año 2015, la ASRM recomendaba que las compensaciones económicas a las donantes por su «tiempo y molestias» se limitaran a $\$ 10.000$, pero esta recomendación fue retirada tras una demanda judicial contra la ASRM por «fijar precios» que fue resuelta en un juicio (Kamakahi vs. ASRM). Mientras que algunas clínicas sí que siguieron la recomendación de los $\$ 10.000$, otras agencias pagaron a sus donantes cantidades muy diversas y se especializaron en «donantes de élite», por ejemplo, donantes con una ascendencia concreta, con estudios en la Ivy League ${ }^{9}$, con talentos especiales o hobbies, o donantes que parecen modelos. Al retirar el límite que recomendaba la ASRM, las compensaciones siguen variando. La ASRM no tiene ningún tipo de recomendación acerca de si los padres intencionales o los médicos deberían ser quienes escogen a las donantes, lo que deja, asimismo, un amplio margen entre una clínica y otra. Pese a que se recomienda que las donantes no se sometan a más de seis ciclos de donación de óvulos -en parte para reducir la cantidad de descendencia resultante de una sola donante y en parte para reducir los posibles riesgos que puedan darse en la salud de la donante-, muchas agencias y clínicas consideran que esa recomendación es más una «sugerencia» que una norma.

Los datos preliminares de la investigación de Tober ponen de manifiesto que la compensación en los Estados Unidos abarca una amplia gama que va desde un mínimo de $\$ 1.000$ a un máximo de $\$ 250.000$; la mayoría recibe una compensación de entre $\$ 5.000$ y $\$ 10.000$, en el primer ciclo. Las clínicas y agencias, normalmente, dan a las mujeres un cheque por la cantidad acordada después de cada uno de los ciclos de extracción. En Estados Unidos, la compensación, habitualmente, se incrementa de forma sustancial conforme se van acumulando ciclos tras haber dado lugar a embarazos exitosos. Y, aun teniendo en cuenta el alto nivel de compensación que reciben las proveedoras de óvulos en Estados Unidos, este pago sigue indicándose como una «compensación por el tiempo y las molestias». No obstante, en Estados Unidos, Hacienda (Internal Revenue Service) ha determinado que la compensación que se da a las donantes es un ingreso gravable (Perez v. Commissioner, 144 T.C. 4, 2015), lo que sitúa a las donantes más en el ámbito del trabajo reproductivo autónomo o de los contratistas independientes que proveen un servicio, que como «donantes» que dan sus óvulos de forma altruista, siendo recompensadas por su tiempo, las molestias ocasionadas o incluso el dolor y el sufrimiento que puedan conllevar los medicamentos y los procedimientos quirúrgicos. Al determinar que las proveedoras de óvulos

\footnotetext{
El término eggonomics utilizado por los autores es una combinación del término egg y economics, de difícil traducción al español. Se refiere a la economía de los óvulos.

9 Así se denomina a un grupo de ocho universidades del nordeste de los Estados Unidos: Brown, Columbia, Cornell, Dartmouth, Harvard, la Universidad de Pensilvania, Princeton y Yale. Estas ocho universidades se encuentran entre las más prestigiosas del país. Aunque originalmente el cometido de la Ivy League era el de promover encuentros deportivos entre las universidades que la componen, ha acabado por convertirse en sinónimo de una educación de prestigio, altamente competitiva y reservada a una élite. https://www.thoughtco.com/ que-es-la-ivy-league-1965350 (Consultado el 28/09/2018).
} 
están ofreciendo un servicio, Hacienda de Estados Unidos se mueve en una fina línea entre la idea de que los óvulos son productos que se venden y se compran -puesto que es ilegal comprar y vender tejidos y órganos humanos-, a la vez que se permite ganar dinero de los cuerpos de las mujeres.

Mientras que algunas proveedoras han luchado contra las directrices de Hacienda y han salido ganando -especialmente aquellas que gastaron más en tratamientos médicos de lo que recibieron como pago, debido a complicaciones vinculadas de forma directa con las donaciones-, otras han sido gravadas con los tipos impositivos más altos correspondientes a los «trabajadores autónomos» o a los «contratistas independientes», que es, aproximadamente, del 30\%. Sin embargo, no todas las proveedoras de óvulos terminan siendo gravadas por este ingreso. Si bien algunas agencias y clínicas facilitan a sus proveedoras formularios de impuestos 1099 que indican cuáles son las ganancias, dando parte así a Hacienda, otras no lo hacen. Algunas proveedoras se anticipan a ello y demandan un pago superior que cubra la cantidad que van a tener que gravar. El hecho de que en Estados Unidos los ingresos de las proveedoras estén siendo gravados aproxima las realidades sistémicas del aprovisionamiento de óvulos mucho más a un «trabajo reproductivo», alejándolo del marco de la donación altruista (Álvarez, 2008, 2010; Tober, 2002, 2018; Tober y Nahman, 2018).

En Estados Unidos -donde el salario mínimo es de unos \$15.000 al año-, la compensación por la provisión de óvulos en un solo ciclo mensual puede ser equivalente a ocho meses de salario o más. En España, donde el salario anual es ligeramente superior a $\$ 12.000$, la compensación máxima permitida es de poco más de $\$ 1.100$ o $1.000 €$ (estadísticas de la OCDE para 2016)- poco más de un mes de salario mínimo-- En España, las proveedoras reciben un sobre que contiene el dinero en metálico poco después de la cirugía de extracción de los óvulos. Este efectivo no puede seguirse en España y, por tanto, no se considera gravable.

Debería considerarse, igualmente, el coste de los estudios universitarios. La matrícula anual en la Universidad de California -que es una institución educativa pública- cuesta anualmente $\$ 13.900$; la matrícula en universidades privadas y en la Ivy League es significativamente superior. En España, los costes de la matrícula en las universidades públicas se mueven en un rango que va desde los $800 €$ hasta los $2.000 €$ al año, pero las universidades privadas pueden cobrar hasta $10.000 €$ (\$11.000) al año. El coste elevado de la educación en Estados Unidos puede ser uno de los principales factores que impulsa el mercado de los óvulos, ya que genera un conjunto creciente de estudiantes agobiadas por la deuda que venden sus óvulos para compensar su deuda educativa. Esta diferencia podría explicar por qué la provisión compensada de óvulos es más común entre las estudiantes estadounidenses que entre las estudiantes españolas. Más del $90 \%$ de las proveedoras del estudio de Tober manifestaban que los gastos de las matrículas universitarias y las deudas de los préstamos estudiantiles eran las razones principales para proveer óvulos. A pesar de las necesidades económicas, la mayor parte de las proveedoras en los Estados Unidos subrayan su deseo de ayudar a otras personas a crear sus familias, pero que no donarían óvulos sin compensación. En España, una encuesta llevada a cabo recientemente por la agencia de óvulos Ovulum sugería, igualmente, que la mayoría de las proveedoras declaraban una combinación de motivaciones altruistas y económicas. Sin embargo, parece que la compensación económica es un factor clave en la biodisponibilidad de las proveedoras de óvulos en España (Ovulum, 2016). La escasez de 
donantes de óvulos en hospitales públicos, donde no se da ningún tipo de compensación, parece confirmar esto, especialmente, si consideramos que las clínicas privadas españolas que compensan económicamente a las proveedoras de óvulos no parecen experimentar ningún tipo de escasez.

\subsection{La selección en el modelo de compensación escalonada vs. el modelo de compensación igualitaria}

En España, los médicos de las clínicas privadas que tratan la infertilidad mediante la donación de óvulos, o bien tienen su programa interno de donación de óvulos o compran los óvulos para sus pacientes a bancos de óvulos - un fenómeno emergente posibilitado gracias a los avances en la tecnología de vitrificación de óvulos-. Sea como sea, es un sistema cerrado en el que el anonimato es obligatorio y las proveedoras y las mujeres receptoras reciben muy poca información las unas de las otras. En parte como resultado de la liberalización de las conductas sexuales y las creencias culturales tras la desaparición de la dictadura de Franco, las prácticas sexuales y reproductivas se han mantenido como algo individualizado e íntimo, con el objetivo de eludir la interferencia de la Iglesia Católica y del Estado. Por esta razón las clínicas privadas de fertilidad prosperan mientras que en el sistema sanitario público los tratamientos de fertilidad no son tan accesibles como otros tratamientos médicos (Pavone y Arias, 2012). Además, en 2012, el gobierno conservador intentó restringir el acceso de madres solteras y parejas de lesbianas a los tratamientos de FIV en el sistema público de salud, argumentando que la ausencia de pareja masculina no era un factor médico. Las indignadas reacciones públicas y la resistencia de algunas autoridades autonómicas lograron preservar el acceso a la FIV de estos grupos, al menos en algunas comunidades autónomas (El País, 18 de julio de 2013 «Excluidas lesbianas y mujeres solas de la reproducción asistida pública»; El País, 14 de octubre 2015, «Valencia devuelve la reproducción asistida a parejas lesbianas y mujeres solas»).

Mientras que en España no hay agencias que proporcionen óvulos donados directamente al consumidor como en Estados Unidos, recientemente han aparecido en el mercado español brokers de óvulos. Ovulum (https://ovulum.com) y Ovodonas (http://ovodonas.com) sirven a clínicas de pequeño y mediano tamaño con una gama de donantes que ellos mismos han captado y organizado en sus propios catálogos. Otras clínicas de mayor tamaño, internacionales con base en España como el IVI, han llevado a cabo investigaciones amplias de mercado y saben cómo reclutar donantes con una alta demanda. El IVI -con oficinas en España, Portugal, Panamá, Chile, Brasil, Argentina, Méjico y Reino Unido, y con alianzas con clínicas en India- ofrece óvulos frescos y congelados, así como óvulos de donantes almacenados/conservados para enviar a escala mundial. Como resultado de ello, un número cada vez mayor de clínicas externalizan la captación de proveedoras de óvulos mediante agentes y bancos, con el objetivo de reducir costes y cargas administrativas. Así, teniendo en cuenta que todas las donantes de óvulos son compensadas de la misma forma, no más de $1.100 €$, y que son los médicos quienes escogen a las donantes en nombre de sus pacientes, se logra minimizar la competencia por donantes específicas.

El sistema estadounidense tiene sus raíces en un modelo de «libre mercado» y de «elección del consumidor» que refleja los valores culturales estadounidenses subyacentes insertos en una medicina en busca de la rentabilidad y el benefi- 
cio. En Estados Unidos, existen múltiples opciones a la hora de encontrar una proveedora de óvulos y de negociar el contacto entre los receptores y las proveedoras. Algunas clínicas de fertilidad tienen sus propios programas internos con un captador de donantes y un coordinador que se encargan de la captación y la organización del programa. Otras clínicas trabajan con una amplia gama de agencias de donación de óvulos; las agencias son negocios no regulados que captan a mujeres para que proporcionen sus óvulos y, en algunos casos, ayudan a emparejar a la donante con la mujer receptora que ellos escogen. Algunas agencias y clínicas trabajan conjuntamente y la clínica deriva a sus pacientes a una agencia para elegir a su donante.

En la mayoría de las agencias y clínicas estadounidenses, las donantes crean perfiles online con el objetivo de que los padres intencionales puedan ver la base de datos y seleccionar sus opciones preferidas. Las donantes crean sus perfiles con ayuda de los captadores y coordinadores de las agencias con la intención de resultar atractivas a los padres intencionales y, entonces, ser seleccionadas. Algunas veces, los profesionales de la agencia incluso llegan a cambiar estos perfiles para hacerlos más atractivos. Por ejemplo, una donante veterana de cinco ciclos afirma:

Miré mi perfil online después de entregarlo para la pregunta «ieres atlética?», escribí «soy una judía total y no soy nada atlética a no ser que cuente que puedo adelantar a personas que caminan muy lento». La agencia lo cambió a «me gusta correr y hacer yoga».

Los perfiles online, habitualmente, incluyen fotos actuales, fotos de cuando eran bebés o niñas, información acerca de sus comidas y hobbies favoritos, así como la altura, el peso, el color de los ojos y la ascendencia. Algunas agencias contratan incluso a profesionales de la fotografía o el estilismo para hacer sesiones de fotos a sus donantes, con el objetivo de que estas sean presentadas de la mejor forma posible. De este modo lo describe una de las donantes, ya en su tercer ciclo de donación, Sophia:

Es marketing. Estas agencias quieren poder decir: «Nuestras donantes son las mejores. Tienen los coeficientes intelectuales más altos. Son las más atractivas»... De modo que cuando redactamos nuestros perfiles, te preguntan cosas como: «iHas fumado alguna vez marihuana?». Si dices «Sí», el captador dirá: «Bueno, tal vez es mejor que no pongas eso si quieres ser escogida».

El sistema estadounidense, basado en el mercado, no solo contribuye a la mercantilización de determinados rasgos, que en ciertas mujeres suponen una mayor demanda y un mayor valor, sino que contribuye a una falsa publicidad. Los incentivos económicos pueden influir en que las proveedoras no siempre proporcionen información sobre ciertos comportamientos y rasgos que podría llevarlas a no ser escogidas (Titmuss, 1997). Pese a que la mayoría son honestas, algunas donantes potenciales pueden ocultar cierta información, o algunos profesionales de la industria pueden indicarles que es mejor no revelar ciertas cosas que podrían reducir sus posibilidades de ser escogidas. 
Algunos padres intencionales han llegado a competir por ciertas «donantes de alta demanda» en un ciclo concreto, y pueden tratar de ofrecer precios superiores que otros receptores o verse obligados a esperar hasta que la donante esté disponible para el siguiente ciclo. Los captadores de las agencias se quejan a menudo de que otras agencias compiten por hacerse con sus donantes, así como que algunas mujeres se apuntan a múltiples agencias al mismo tiempo. Este tipo de sistema incentiva, igualmente, que las proveedoras de óvulos intenten llevar a cabo ciclos consecutivos tan rápido como les sea posible, haciéndolo incluso antes de tener tiempo para recuperarse. Kim, una mujer de 25 años que ha proporcionado sus óvulos tres veces, explica:

Es algo así como un empleo en el que puedo trabajar durante tres semanas y después obtener otro pago de $\$ 10.000$. Y sabes que ese dinero está ahí, tan solo a unas pocas semanas en el caso de necesitarlo. Las clínicas te despachan con un pack de píldoras anticonceptivas para prepararte inmediatamente para el siguiente ciclo tras la extracción. De modo que una siente una cierta presión de simplemente ir y hacerlo, especialmente cuando eres consciente de que hay alguien ahí fuera que cuenta contigo.

La experiencia de Kim nos señala múltiples elementos a estudiar. Por una parte, para ella y para otras muchas proveedoras de óvulos como ella -a pesar del lenguaje de la donación y el altruismo-, el suministro de óvulos es un empleo y a la vez no lo es. No puede depender de ello como un ingreso fijo durante toda la vida, pero es un ingreso temporal suficiente para incentivarla a seguir haciéndolo. Por otra parte, experimenta un sentido de responsabilidad con los receptores que compran sus óvulos, sabe que cuentan con ella y no quiere fallarles. A las donantes de óvulos en Estados Unidos se les suele transmitir la información suficiente de las historias de los receptores para generar empatía con ellos, y sus emociones se manejan, durante el proceso de donación de óvulos, a través de sus interacciones con el personal clínico y la agencia (Tober y Kroløkke, de próxima publicación). La mayoría de las proveedoras de óvulos informan sentirse muy implicadas en el resultado deseado de sus padres de intención -lograr un embarazo exitoso-.

Las percepciones de lo que es la donante ideal influyen a la hora de buscar a las proveedoras de óvulos en el mercado estadounidense. Las donantes rubias y con ojos azules son especialmente demandadas. Algunas agencias de provisión de óvulos en Estados Unidos se especializan en donantes «difíciles de encontrar»-incluyendo a donantes con ascendencias concretas, tales como asiáticas o judías-, mujeres que son consideradas especialmente atractivas físicamente o con rasgos concretos, con un gran éxito académico o con talentos en las áreas del deporte o de la música. Algunas mujeres que saben que pueden ser muy demandadas - mujeres consideradas físicamente atractivas y estudiantes de las universidades de la Ivy League- buscarán agencias conocidas por pagar más o aprenderán a negociar sus honorarios. De este modo, las proveedoras expertas pueden maximizar así sus ganancias con el objeto de beneficiarse económicamente de la demanda del mercado.

Renee es una proveedora de 25 años, rubia, atractiva y con estudios. Se interesó en la donación de óvulos tras una conversación con su tío gay y su marido que estaban intentado formar una familia mediante gestación subrogada y donación de óvulos. Pero ella sabía que solo suministraría sus óvulos bajo ciertas condiciones: 
Investigué un montón de agencias. Para mi primer ciclo, lo hice con una agencia, pero no pagaban demasiado. Tan solo recibí $\$ 6.500$ por mi primer ciclo, que estaba bien, pero no parecía demasiado comparado con todo lo que tuve que pasar. Era una donante muy demandada en las dos agencias a las que me presenté. Aparecieron unas seis parejas interesadas en mi perfil tan pronto como este salió.

De modo que empecé a pensar que, en realidad, preferiría conseguir $\$ 8.000$ o $\$ 10.000$ por cada ciclo. Y mi novio dijo: «¿Y por qué no \$18.000 o \$20.000?» De modo que me situé en un punto intermedio: haría una donación local por $\$ 12.000$, y por cada donación que requiriese viajar serían $\$ 15.000$. Y parte de mis razones por poner precios más altos fue que me sentía un poco ambivalente en relación a hacerlo de nuevo. Tuve que sopesar, ¿en qué punto dejaría de merecerme la pena?

A las proveedoras de óvulos con una alta demanda como Renee, se les pide que hagan ciclos seguidos, con poco tiempo para que sus cuerpos se recuperen entre un ciclo y otro. Es posible que los padres intencionales hagan cola, esperando a que la donante que han escogido finalice su último ciclo para que empiece el siguiente. Además, las «donantes probadas»-mujeres cuyos óvulos han dado lugar a embarazos exitosos- pueden negociar compensaciones más altas en los siguientes ciclos. Por ejemplo, si ha ganado $\$ 7.500$ en su primer ciclo y la madre intencional o la gestante subrogada concibe, recibirá $\$ 10.000$ en su siguiente ciclo e irá aumentando en cada ciclo. Los incentivos económicos, más el sentimiento de no querer fallar a los padres intencionales, lleva a las donantes a continuar con múltiples ciclos, cuando es posible que no lo hicieran de otro modo.

Los pacientes son consumidores que seleccionan a las donantes basándose en los rasgos deseados. Los captadores de donantes buscan de forma activa a donantes que encajen en estas demandas, ya sea mediante anuncios online o yendo a universidades o eventos a los que acuden mujeres jóvenes. Los óvulos -y por extensión las mujeres que los proveen- son productos en un sistema en el que algunas personas tienen más valor que otras. El modelo estadounidense de «elección del paciente» da lugar a un mercado escalonado de óvulos humanos -ampliando un programa eugenésico blando-, en el que a algunas mujeres se las percibe con un valor dramáticamente superior al de otras. Irónicamente, estas mujeres soportan el peso de un mayor riesgo médico como proveedoras de un mercado de óvulos de alta demanda. Annemarie Mol ha abordado cómo las dinámicas de «elección del paciente» y «buena atención» pueden chocar, a menudo, en el contexto de la asistencia sanitaria (Mol, 2008: 1). Este parece ser el caso también en el mercado de óvulos en Estados Unidos, donde la elección del consumidor crea un mercado escalonado de óvulos humanos y las proveedoras populares de óvulos se someten a ciclos consecutivos uno detrás de otro.

La selección de donantes en España sigue un modelo muy diferente al de Estados Unidos. De acuerdo con la regulación nacional, la donación es anónima y altruista y solo pueden nacer un máximo de seis niños por donante. Esta limitación se introdujo en un primer momento, para limitar el riesgo de consanguinidad pero también para reducir los riesgos vinculados a llevar a cabo múltiples donaciones de óvulos. En España, el aprovisionamiento de óvulos debe ser «altruista», por lo que las proveedoras reciben una compensación fija por su tiempo, molestias y salarios perdidos, pero 
no lo suficientemente alta como para incentivar a las mujeres a seguir donando sus óvulos. Además, las clínicas no pueden llevar a cabo diferenciaciones en la compensación en función de sus características sociales y físicas o en función de la cantidad de óvulos que les han extraído. A los receptores tampoco se les permite escoger a sus donantes; en España, son los médicos quienes seleccionan a las donantes en lugar de sus pacientes, y suelen hacerlo, únicamente, en función de las similitudes fenotípicas entre las donantes y las madres intencionales. Los médicos deben seleccionar a las donantes de acuerdo con los siguientes criterios: coincidencia del tipo de sangre, color del pelo, color de los ojos, color de la piel y complexión física. Esto es lo que Mario, coordinador de un banco de óvulos, comentaba:

Cuando se lo explicas le dices que tienes que buscar alguien que sea compatible fenotípicamente porque es usted... obviamente es como si fuese a tener un hijo suyo, mismo color de ojos, color de pelo, grupo sanguíneo, raza, altura, complexión que usted.

Aun así, las donantes blancas y rubias, con estudios universitarios o con una educación o talentos concretos, también son altamente deseadas en España; pero ellas no reciben más compensación por su expediente académico o por sus rasgos físicos. Al contrario que en Estados Unidos, las donantes en España no rellenan perfiles detallados con fotografías y otra información que puedan ver los padres intencionales. Estos reciben muy poca información de su donante, solo que han pasado las pruebas médicas, que tienen buena salud y que se parecen a los padres de intención. Así es como María, una ginecóloga de una gran clínica, lo explicaba:

Pero lo que se les dice y cuando vienen aquí a por una ovodonación ya lo tienen claro. Te ofrecemos características físicas. Si eres caucásica es caucásica, si tienes la piel pálida tendrá la piel pálida a menos que a ti te dé igual que sea morena. Es que intentamos que la donante se parezca a su receptora. No al cien por cien pero que tenga... [Luego hay] ese que vienen inicialmente pidiendo que tengan la nariz fina, ¿vale? Si tenemos una... todo esto y tiene la nariz fina pues, ¿por qué no? Si tú la tienes así finita y bonita. Pero si no tiene una nariz tan fina te lo diremos, esta no tiene la nariz tan fina, «bueno, da igual». Esas son las garantías que ofrecemos, otra cosa no hacemos.

Pese a que la cantidad de información que se obtiene de las donantes es muy limitada, muchos padres intencionales intentan conseguir tanta información como les es posible. En algunas clínicas, existe un grado limitado de negociación, especialmente, con relación a las aptitudes sociales y educativas y otras características de las donantes (Lafuente, 2017). Más específicamente, algunos pacientes potenciales buscan donantes universitarias, donantes con aptitudes musicales o intereses especiales. Laura, ginecóloga de una clínica mediana, explicaba la negociación en los siguientes términos:

No se puede elegir, en España no se puede elegir a la donante, pero sí que se puede pedir, «mira, yo preferiría una que sea universitaria». Pues no se le dice que no, se 
le dice «mira, tengo un $10 \%$ de universitarias, esperar a la universitaria te puede costar meses [...]». Si pides un perfil concreto o que le guste, qué sé yo, la música o las fotos, pues sí, se puede mirar, sí, por qué no, pero hay que esperar más.

El personal también presta especial atención a la eliminación de candidatas con enfermedades psicológicas y perfiles psicológicos poco convincentes, e intenta seleccionar perfiles socialmente deseables, rechazando a proveedoras con malos hábitos sociales o sexuales (fumar, beber, ser promiscua) o a aquellas que se visten y se comportan de forma excéntrica. Ana y Elena, ginecólogas de dos diferentes clínicas de tamaño medio, hablaban de este proceso en estos términos:

Ana: Entonces, imagínate que son mujeres que declaran que han tenido un tratamiento psiquiátrico o que han tenido alguna vez ideas de suicidio o que tienen una vida absolutamente inestable con parejas múltiples cada dos meses. Si tú ves que hay en la entrevista en su entorno algo que te llama la atención con la intención de no introducirlas en el programa.

Elena: En ese cuestionario miramos también mucho que tú veas que son gente normal, que no sea... O sea, gente que tú veas que son comprometidas, que son serias, que son responsables. Que también a la hora de hablar con ellas veas que tienen la cabeza bien centrada, que no son unas locas que van diciendo por ahí voy a donar óvulos y... no sé, con cincuenta piercing. La donante perfecta es por debajo de los treinta años, que no tenga ningún tipo de hábito, que no fume. El tabaco intentamos coger que no fume, que no beba. Para mí una donante perfecta es aquella que tiene una formación de estudios mediossuperiores y que en el estudio que le pedimos y la ecografía que le hacemos tenga folículos antrales por encima de diez.

Al igual que en Estados Unidos, las donantes probadas también son muy demandadas en España. Sin embargo, no se les puede pagar más simplemente por haber demostrado su fertilidad; sí que son incluidas en un catálogo especial, de modo que pueden ser contactadas de nuevo para futuras donaciones. Teniendo en cuenta estas limitaciones, los padres intencionales de otros países que desean una selección más amplia, pueden viajar a otros sitios para acceder a una amplia variedad de donantes y escoger entre ellas, como en Estados Unidos. Al contrario, los padres intencionales de países en los que el anonimato está prohibido, como Reino Unido, pueden viajar a España para tener una donante anónima. Puesto que las regulaciones en España limitan la compensación que se le da a la donante y los médicos escogen a las donantes, España consigue evitar el mercado estratificado de donantes de óvulos que sí existe en Estados Unidos. Este modelo de compensación más equitativo también supone que las donantes potenciales tienen menos incentivos monetarios que sus homólogas estadounidenses.

Esto no quiere decir que en España no haya ciertos sesgos en la selección de donantes. Varios captadores de clínicas señalan que han buscado a mujeres rumanas, ucranianas y de otras zonas del Este de Europa para que fueran proveedoras, por 
encima de donantes inmigrantes de países latinoamericanos. Un captador explicaba a Tober que las donantes europeas -y en particular las mujeres blancas, rubias y con ojos azules- «parecen más españolas» que mujeres latinoamericanas con «aspecto más indígena» (ver también Lafuente, 2017). Además, como España proporciona servicios a padres intencionales de Reino Unido, Francia, Alemania e Italia (Bergmann, 2011; SEF, 2015), las donantes más blancas tienden a encajar mejor con las demandas fenotípicas de un mercado europeo más amplio.

\subsection{Crioconservación, almacenamiento y el negocio cambiante de la provisión de óvulos}

Los avances en las tecnologías de congelación de óvulos han revolucionado también la industria de la donación de óvulos, con implicaciones importantes para las bioeconomías reproductivas (Cooper y Waldby, 2014; Petropanagos et. al., 2015; Inhorn, 2017; Pavone, 2017). Las mujeres ya no solo escogen congelar y almacenar sus propios óvulos, sino que la capacidad de congelar y depositarlos ha abierto nuevos modelos de negocios para las clínicas que proporcionan servicios de donación de óvulos, y ha dado lugar a bancos de óvulos, similares a los bancos de esperma.

Ovobank, un banco de óvulos español, por ejemplo, ofrece el envío de óvulos vitrificados a toda Europa, y esto es especialmente importante para el mercado italiano, donde la donación de óvulos se permite pero donde hay una escasez absoluta de donantes debido a la ausencia de una compensación económica (Corriere della Sera, 28/11/2016). El almacenamiento de óvulos como alternativa a los ciclos de donación en fresco en los que se empareja a una sola donante con una madre intencional, tiene consecuencias para la práctica médica y la atención a la donante: cuando las donantes producen una gran cantidad de óvulos, hay más óvulos disponibles para vender a más padres intencionales y se genera un mayor beneficio potencial para los bancos de óvulos.

La vitrificación ha favorecido la aparición de diferentes modelos de negocios para la provisión de óvulos, incluyendo tanto ciclos «compartidos» de donación de óvulos como ciclos para bancos de óvulos, además del ciclo tradicional uno a uno. En un ciclo de uno a uno, los receptores se emparejan con una única donante y reciben todos los óvulos que produce en ese ciclo. En un ciclo «compartido» de donación de óvulos, dos o más mujeres o parejas receptoras son emparejadas con una sola donante a un precio reducido. En vez de recibir todos los óvulos -como sucedería en una donación uno a uno-, en los ciclos compartidos, los óvulos son vendidos en lotes pequeños a cambio de un coste menor. Si quedan óvulos, se pueden congelar y revender en lotes para descongelarlos y usarlos posteriormente. En España se suele hacer referencia a esto como «minidonación». La proveedora de óvulos no recibe una compensación superior por llevar a cabo ciclos compartidos, a pesar del hecho de que las clínicas obtienen beneficios significativamente más altos. Las mujeres proveedoras de óvulos para bancos de óvulos pasan por un ciclo de donación y extracción, pero no son emparejadas inmediatamente con ninguna mujer o pareja receptora, sino que sus óvulos son congelados, almacenados y vendidos más tarde. En Estados Unidos, pueden ser vendidos directamente a los receptores pero en España son vendidos congelados directamente a las clínicas. En estas prácticas, los óvulos pertenecen estrictamente al banco, y la proveedora no recibe ningún tipo de infor- 
mación acerca de los receptores que los compran o de si algún niño ha nacido de su donación. Desde la perspectiva mercantil de estos bancos, las donantes que producen una gran cantidad de óvulos son especialmente atractivas.

Candace tenía 19 años cuando empezó a interesarse por la donación de óvulos. Encontró un anuncio en Pandora, un espacio muy conocido para escuchar música. Se hizo donante de óvulos porque quería ayudar a otras mujeres como su madre, que había luchado contra la infertilidad secundaria. Candace dio sus óvulos a un banco en Nueva York.

Cuando rellené la solicitud, ni siquiera sabía qué compensación me iban a dar. Pensé que sería algo como $\$ 5.000$, y cuando fui allí no me dijeron demasiado acerca del dinero. Eso me gustó porque no quería sentir que solo era asunto de dinero. De modo que me dijeron que mis óvulos iban a ir dirigidos a cuatro o cinco familias diferentes. No solo a una. Me explicaron que los receptores reciben lotes de seis óvulos, y como en mi primera donación me dijeron que produje 31 óvulos maduros, creo que en torno a cuatro o cinco familias obtuvieron mis óvulos.

Diferentes clínicas poseen modelos distintos respecto al modo de compensar a las donantes y a cómo los óvulos son repartidos en lotes y distribuidos. Una clínica de Los Ángeles tenía una gama de opciones para satisfacer las necesidades financieras de sus clientes, que incluyen: ciclos de óvulos frescos uno a uno, ciclos de óvulos frescos compartidos y óvulos congelados y almacenados. En un ciclo de donación uno a uno, los padres intencionales contratan a una sola donante para utilizar sus óvulos. La donante puede recibir $\$ 7.500$, y todos los óvulos se convierten en embriones para esos padres. En el caso de una donación exclusiva, los padres intencionales pagan entre $\$ 26.000$ y $\$ 30.000$ a la clínica. Mediante este pago, pasan a ser propietarios de los óvulos y embriones y, por tanto, pueden decidir hacer con ellos lo que quieran.

En un ciclo compartido de óvulos frescos, una sola donante es emparejada con dos o tres padres intencionales, a cada uno de los cuales se les garantiza un lote de 5 ovocitos frescos por un precio reducido de $\$ 18.000$ cada uno -una opción más económica que la donación uno a uno-- Si pensamos en tres padres intencionales por cada donante, la clínica recibe aproximadamente $\$ 54.000$ para cada uno de los ciclos de donación de óvulos frescos. De todo ello, la donante recibe un único pago de $\$ 7.500$-lo mismo que hubiera cobrado en una donación exclusiva- y la clínica todavía puede vender lotes de óvulos sobrantes congelados a otros padres intencionales. Mediante este modelo de donación compartida, una donante podría producir 30 óvulos que serían vendidos por la clínica en tres lotes de óvulos frescos a $\$ 18.000$ cada uno, siendo los 15 restantes divididos en lotes de 5 que son vitrificados, almacenados y vendidos por el mismo precio, de tal manera que la clínica conseguiría ganar $\$ 108.000$ en un solo ciclo de donación sin aumentar el pago a la donante. Mediante una donación exclusiva, con el mismo número de óvulos producidos, la clínica obtendría \$26.000. En este escenario de donaciones compartidas, cada óvulo tiene un valor, aproximadamente, de $\$ 3.466$. Si la misma donante produjera una cantidad mayor de óvulos maduros, los beneficios de este ciclo aumentarían proporcionalmente, mientras que a la donante se le seguiría pagando la misma cantidad de $\$ 7.500$. La donación compartida, al emparejar a una donante con múltiples receptores, supone un enorme beneficio para las clínicas que poseen estos programas. 
Leena, una mujer asiática, pequeña y atractiva, primero pensó en donar óvulos cuando vio un anuncio en Craigslist que ofrecía $\$ 10.000$ a las donantes con ascendencia asiática; como alumna de la Universidad de California con altas notas en el examen de ingreso a la universidad, cumple con los criterios que buscaba una agencia asiática de élite de donación de óvulos. Empezó su primer ciclo de donación con 19 años, realizando un total de cuatro donaciones entre los 19 y los 20 años. Una clínica local que trabajaba con su agencia contactó con ella poco después de que activara su perfil online, señalando que quería llevar a cabo una «donación de óvulos vitrificados» con ella.

Leena: Prácticamente en cuanto me «activé», una clínica de Los Ángeles me contactó y dijo que querían mis óvulos. Dijeron que querían vitrificar mis óvulos y repartirlos entre diferentes parejas de padres intencionales con el objetivo de hacerlos más accesibles económicamente -lo que ellos llamaban un «ciclo compartido»-, y por el que me pagarían $\$ 6.500$. Sin embargo, esto me hizo sentir como que mis óvulos eran óvulos «low-cost», me pareció un poco turbio.

P: ¿Cuántos óvulos produjiste en cada ciclo?

Leena: Durante mi primer y mi segundo ciclo produje entre 30 y 32 óvulos, en el tercero 22, y en el cuarto algo así como 40. Era una cantidad increíble, me sentía muy incómoda y estaba muy preocupada por el síndrome de hiperestimulación ovárica. De modo que les dije que no quería que cogieran demasiados óvulos, pero ellos simplemente ignoraron mis inquietudes. Después de eso decidí que no lo iba a hacer más.

Si una donante produce una gran cantidad de óvulos, el médico puede decidir reducir la medicación para intentar reducir el número de óvulos que maduran. Sin embargo, en las donaciones compartidas - especialmente en el caso de que los óvulos restantes puedan ser vitrificados, almacenados y vendidos-algunos continúan con el ciclo tal como está, independientemente de la cantidad de óvulos que lleguen a la madurez, y lo justifican diciendo que una «inyección desencadenante» de Lupron TM reduce el riesgo de complicaciones en las donantes. Las proveedores de óvulos en el estudio de Estados Unidos informan que producen un promedio de 24 óvulos maduros/por ciclo, con un rango entre 6 como poco y 80 como mucho en un solo ciclo. En España, la media de óvulos extraídos ha pasado de 12 a 16 en tan solo 6 años (SEF, 2009; SEF, 2015). En Estados Unidos, no tenemos números nacionales de extracción de óvulos, ya que no hay una base de datos central que recopile esta información.

Lucy $^{10}$ es una captadora de donantes de óvulos y gerente de una de las agencias de donación de óvulos en Los Ángeles. La agencia que ella dirige está estrechamente vinculada con la clínica de fertilidad con la que comparte oficina. Lucy explica cómo capta a las donantes para sus ciclos compartidos y los programas de donación de óvulos vitrificados:

10 Lucy fue entrevistada y grabada con una cámara para la película documental de Tober: The Perfect Donor (La donante perfecta) (http://theperfectdonor.com). 
Lucy: Nosotros siempre nos tenemos que basar en los resultados del test de reserva ovárica porque no queremos arriesgar a la donante a una hiperestimulación tan solo porque queramos más óvulos. Atendemos a la prueba y decimos: «guau, va a ser una gran productora». Si los resultados no son tan buenos como nosotros esperamos, entonces esa donante es inhabilitada del programa de donación compartida, pero sigue pudiendo participar en un ciclo de uno a uno.

P: ¿Cuántos óvulos esperáis que produzcan las donantes?

Lucy: La media es de unos 15 o 20, pero hemos visto números de setenta y tantos, especialmente, en nuestro programa compartido. Y estoy segura de que ni siquiera es el número más alto que se puede encontrar.

Mientras que «el ciclo compartido» supone un modelo de negocio rentable, también tiene importantes implicaciones para la atención médica. Las entrevistas preliminares realizadas indican que: a) las mujeres que producen de forma natural grandes cantidades de folículos son, muy a menudo, seleccionadas para los programas de donación compartida; y b) en algunas clínicas, las donantes de ciclos compartidos son estimuladas para producir mayores cantidades de óvulos. Ambos factores representan un mayor riesgo para las donantes de sufrir complicaciones.

Si bien los datos son preliminares, el modelo comercial de provisión de óvulos de Estados Unidos puede llevar a diferentes experiencias y resultados para las donantes de óvulos estadounidenses en comparación con sus homólogas españolas, incluyendo una mayor producción de óvulos y mayores complicaciones asociadas en las proveedoras de Estados Unidos. Se necesita más investigación en esta área. Aunque no tenemos evidencia alguna de que se estén dando prácticas similares en España, la media de óvulos extraídos en cada ciclo ha aumentado de 12 en 2009 a 16 en 2015 (SEF, 2009; SEF, 2015). La media de óvulos extraídos en España, comparativamente inferior comparada con la de Estados Unidos, fundamenta nuestra preocupación de que el modelo de negocio de las clínicas estadounidenses puede llevar a protocolos hormonales más altos y a mayor exposición a fármacos para incrementar la fertilidad, lo que podría aumentar el riesgo para las donantes.

En España, pese a que el coste de extraer óvulos de una sola donante sigue siendo fijo, las oportunidades que ofrecen la vitrificación y almacenamiento de óvulos permiten la preservación y redistribución posterior de óvulos a más de una receptora. Sara, ginecóloga de Barcelona, lo explica así:

Bueno, hay una donante solo para ti o una donante compartida. Tú cuando contratas pues contratas la ovodonación normal o la ovodonación básica. La ovodonación básica te garantiza cuatro óvulos inseminados. Y esos [los] cogemos [de] sobras de donantes que han dado muchos o... [de] Una donante que ha dado quince pues igual le doy diez a una y cuatro...

Esto sugiere que en España también se está produciendo un importante cambio en el modelo de negocio: los bancos comerciales de óvulos, como Ovobank, cada vez exportan más óvulos a otros países europeos. Los brokers de óvulos brindan nuevos servicios, a medida que las clínicas externalizan cada vez más el suministro de los proveedores de óvulos. En este sentido, España es cada vez más similar a Ucrania, 
donde la provisión de óvulos se organiza como un esfuerzo comercial más explícito (Vlasenko, 2015, 2016).

\section{Conclusión}

Las investigaciones comparativas entre las bioeconomías reproductivas y los mercados médicos especializados en óvulos humanos, úteros y esperma, reflejan el modo como el sistema capitalista global opera en los cuerpos de los individuos. La desigualdad económica de clase, raza y poder se materializan en el mercado reproductivo. Si bien las regulaciones locales, o la falta de ellas, iluminan y ponen de manifiesto mundos morales y éticos e intentan limitar las violaciones morales, las empresas que buscan ganancias pueden desafiarlos y desplazar las salvaguardas regulatorias que han sido establecidas. Estudiando el modo en que el mercado de óvulos opera en estos dos contextos culturalmente distintos -en los que se permite la compensación a las donantes en diversos grados-, obtenemos un conocimiento de los fundamentos éticos de las políticas y los mundos morales locales.

En el caso de Estados Unidos, en donde la libertad de empresa y la elección del consumidor son prioritarios, el mercado de óvulos refleja unos principios culturalcorporativos firmemente más amplios que tienen un impacto directo sobre las mujeres jóvenes como productoras de óvulos y, en algunas clínicas, sobre la atención médica que reciben. Aun así, el lenguaje altruista de la «donación» y la compensación «por el tiempo y las molestias», -en lugar de hablar de «venta de óvulos»-, permea aún todo el discurso médico, ya que la venta de seres humanos, productos corporales, órganos y tejidos humanos se considera moralmente reprobable. En España,-donde se tiene en alta estima la atención médica pública, existe una industria reproductiva comparativamente más regulada y una postura más suavizada con respecto a cómo las donantes son seleccionadas, compensadas y estimuladas hormonalmente-, la posibilidad de vitrificar y almacenar los óvulos está generando, sin embargo, ciertas presiones sobre las proveedoras, que no existían previamente (Inhorn, 2017).

El mercado de óvulos depende de mujeres jóvenes en situación de marginación económica, que proporcionan sus óvulos a cambio de un pago. En Estados Unidos, uno de los descubrimientos más destacables es la medida en la que el pago de las matrículas universitarias y las deudas resultantes empuja a las mujeres a ser proveedoras. Esto plantea serias preocupaciones de que el continuo aumento del coste de la educación universitaria en Estados Unidos es directamente responsable de crear una fuerza de trabajo reproductiva estudiantil biodisponible. En España, las estudiantes suelen ser donantes potenciales, pero no son captadas en la misma medida que en Estados Unidos. Las economías locales, las limitaciones y las estructuras institucionales se entrecruzan con los biomercados locales y globales.

Estos diferentes contextos regulatorios tienen un impacto enorme en el modo en que las mujeres son captadas, seleccionadas y compensadas. Con el énfasis en Estados Unidos sobre el libre mercado, la elección del consumidor y la oferta/demanda $-\mathrm{y}$ el hecho de que los padres intencionales seleccionan a las donantes de su futuro hijo-, la calidad mercantil de los óvulos y de las mujeres que los proveen llega a puntos inesperados. Los óvulos de algunas mujeres tienen un mayor valor económico que los de otras, reflejando así una bio-jerarquía y presionando a las proveedoras con «rasgos altamente demandados» a llevar a cabo donaciones una tras otra. Mientras 
que las proveedoras en Estados Unidos reciben pagos mucho más altos que las españolas, su compensación se ve, en cierto modo, disminuida por el alto coste de los estudios universitarios. Al mismo tiempo, las limitaciones españolas a la compensación disminuyen el grado en que las mujeres pueden beneficiarse económicamente, mientras que la industria sigue floreciendo.

Este artículo plantea cómo las técnicas de vitrificación pueden estar generando nuevos riesgos médicos para las mujeres que proveen óvulos en mercados locales y globales a cambio de un pago. Además, pone de manifiesto las normas de género y valores culturales subyacentes que rodean a quien es apto para la reproducción, incluso si no se monetizan de la misma manera. El sistema estadounidense, sin embargo, sirve de ejemplo de cómo la demanda de óvulos por parte del mercado -empujada en parte por la selección de las donantes que hacen los receptores, la alta compensación y el valor económico de cada óvulo-, puede influir en la práctica médica de algunas clínicas y bancos de óvulos. Nuestro trabajo demuestra la necesidad de más investigación colaborativa, comparativa e internacional para examinar cómo las bioeconomías reproductivas locales se cruzan con la salud y el bienestar de las terceras partes proveedoras. Se necesita más investigación para comparar las experiencias de las proveedoras de óvulos en diferentes entornos culturales y normativos. Este trabajo continuo tiene implicaciones significativas para los responsables políticos, los profesionales médicos, los padres de intención y las mujeres que consideran la provisión de óvulos.

\section{Referencias bibliográficas}

Ahuja, KK; Simons, E.G; Edwards, R.G. (1999). «Money, Morals and Medical Risks: Conflicting Notions Underlying the Recruitment of Egg donors». Human Reproduction, 14: 279-84.

Álvarez Plaza, Consuelo (2008). La búsqueda de la eterna fertilidad. Mercantilismo y altruismo en la donación de semen y óvulos. Alcalá La Real: Alcalá Grupo Editorial.

- (2010). «Pertenencia, identidad y trabajo reproductivo en la reproducción asistida: donantes de gametos y niños agámicos», en R. Díaz y A. González (coords.), Naturaleza, cuerpos y culturas. Metamorfosis e intersecciones. Universidad Autónoma Metropolitana, Unidad Iztapalapa: Juan Pablos Editor, 111-140.

American Society for Reproductive Medicine (ASRM) Ethics Committee Report (2007). «Financial Compensation of Oocyte Donors». Fertility and Sterility, 88:2:305-309.

American Society for Reproductive Medicine (ASRM) Ethics Committee Report (2013). «Cross-Border Reproductive Care: A Committee Opinion». Fertility and Sterility, 100, 3: 645-650.

Balen, Adam (2008). Ovarian Hyperstimulation Syndrome: A Short Report for the HFEA. http://www.hfea.gov.uk/docs/OHSS_UPDATED_Report_from_Adam_Balen_2008.pdf (Última consulta 7 de agosto, 2013).

Basten, S; Sobotka, T. ; Zeman, K. et al. (2014). «Future fertility in low fertility countrie», en W. Lutz; W. P. Butz y Samir KC (eds.), World Population and Human Capital in the Twenty-First Century. Oxford University Press, Oxford, pp. 39-146.

Baylis, Françoise (2014). «Transnational commercial contract pregnancy in India», en F. Baylis y C. McLeod (eds.), Family Making: Contemporary Ethical Challenges. Oxford University Press, Oxford, 265-286. 
Beeson, Diane; Lippman, Abby (2006). «Egg Harvesting for Stem Cell Research: Medical Risks and Ethical Problems». Reproductive BioMedicine Online, 13, 4: 573-79.

Beeson, Diane; Darnovsky, Marcy; Lippman, Abby (2015). "What's in a name? Variations in terminology of third-party reproduction». Reproductive BioMedicine Online, 13:6: 805-814.

Bergmann, Sven (2011). «Reproductive Agency and Projects: Germans Searching for Egg Donation in Spain and the Czech Republic». Reproductive BioMedicine Online, 23, 5: 600-08.

BOE. (2006). Legislación consolidada sobre técnicas de reproducción humana asistida. BOE núm. 126, de 27 de mayo de 2006. Referencia: BOE-A-2006-9292

CDC. (2010). Center for Disease Control and Prevention. Assisted Reproductive Technology. www.cdc.gov/art/ART2010/section4.htm

CDC. (2015). Center for Disease Control and Prevention. Assisted Reproductive Technology. National Summary Report.

https://www.cdc.gov/art/pdf/2015-report/ART-2015-National-Summary-Report.pdf.

Chatterjee, Pyali; Mondal, Debmita. (2014). Trade in Human Eggs: A Current Trend of Reproductive Organ Trafficking. https://www.researchgate.net/publication/268518255 TRADE_OF_HUMAN_EGGS_A_CURRENT_TREND_OF_REPRODUCTIVE_ ORGAN_TRĀFFICKING

CNN. (2013). http://www.cnn.com/2013/09/16/world/international-adoption-main-storydecline/index.html

Cohen, Lawrence (2001). «The Other Kidney: Biopolitics Beyond Recognition», en N. Scheper-Hughes y L. Wacquant (eds.), Special edition, Body and Society, 7 (2-3): 9-29.

- (2005). «Operability, Bioavailability, and Exception», en A. Ong y S. J. Collier, (eds), Global Assemblages: Technology, Politics and Ethics as Anthropological Problems. Malden, MA: Blackwell, 79-90.

Cohen, Jacques; Scott, Richard; Alikani, Mina et al. (1998). «Ooplasmic Transfer in Mature Human Oocytes». Molecular Human Reproduction, 4(3): 269-280.

Cooper, Melinda (2006). Life as Surplus: Biotechnology and Capitalism in the Neoliberal Era. Seattle: University of Washington Press.

Cooper, Melinda; Waldby, Catherine (2014). Clinical Labor. Durham and London: Duke University Press.

Corriere della Sera (2016). Il viaggio degli ovuli dalla Spagna: «Ho 60 contratti con le cliniche italiane», por Simona Ravezzi, 28 Noviembre 2016. Accessible at: http://www. corriere.it/video-articoli/2016/11/28/viaggio-ovuli-spagna-ho-60-contratti-le-clinicheitaliane/56edad9e-b590-11e6-a2c1-e1ab33bf33ae.shtml

Daniels, Cynthia R.; Heidt-Forsythe, Erin (2012). «Gendered eugenics and the problematic of free market reproductive technologies: Sperm and egg donation in the United States»». Journal of Women in Culture and Society, 37: 719-47.

Deomampo, Daisy (2016). Transnational Reproduction: Race, Kinship, and Surrogacy in Rural India. NYU Press: Nueva York.

Der Spiegel. (2013). «Spain in Crisis Becomes Fertility Destination». http://www. spiegel.de/international/europe/spain-in-crisis-becoming-a-center-of-in-vitrofertilization-a-898830.html

Fox, Renee; Swazey, Judith, P. (2013). Spare Parts: Organ Replacement in American Society. Transaction Publishers: Nueva York y Londres.

Franklin, Sarah (2013). Biological Relatives: IVF, Stem Cells, and the Future of Kinship. Durham y Londres: Duke University Press. 
García Cuesta, Sara; Hernández Corrochano, Elena (2015). «Commodity Populations: A Reflection from the Perspective of the Research Process on Sexual Trafficking in Spain». Journal of Feminist, Gender and Women's Studies, UAM. 1: 15-27.

Ginsburg, Faye; Rapp, Rayna (1996). Conceiving the New World Order: The Global Stratification of Reproduction. Berkeley: University of California Press.

González Pineda, Borja (2015). «Maternidad subrogada: realidad actual, problemas y posibles soluciones». TFG, Grado en Derecho, Universidad Miguel Hernández. http:// hdl.handle.net/11000/2309

Guidice, Linda; Santa, Eilen; Pool, Robert (eds.) (2007). Assessing the Medical Risks of Human Oocyte Donation for Stem Cell Research. Workshop Report. Institute of Medicine and National Research Council of the National Academy of Sciences.

Inhorn, Marcia (2003). «Global Infertility and the Globalization of New Reproductive Technologies: Illustrations from Egypt». Social Science and Medicine, 56 (9): 1837-51.

- (2017). The Egg Freezing Revolution? Gender, Technology and Fertility Preservation. Emerging Trends in the Social and Behavioral Sciences: An Interdisciplinary, Searchable, and Linkable Resource.

Institute of Medicine Report (2006). Assessing the Medical Risks of Human Oocyte Donation for Stem Cell Research. Workshop Report. Washington, DC: National Academies Press.

Jociles, María Isabel (ed.) (2016). Revelaciones, filiaciones y biotecnologías. Una etnografía sobre la comunicación de los orígenes a los hijos e hijas concebidos mediante donación reproductiva. Barcelona: Ediciones Bellaterra.

Johnson, Katherine M. (2017). «The price of an egg: oocyte donor compensation in the US fertility industry». New Genetics and Society, 36: 354-74.

Kawwass, Jennifer; Kissim, D.M.; Kulkami,A.D. et al. (2013). "Safety of Reproductive Technology in the United States, 2000-2011". Journal of the American Medical Association (JAMA), 313 (1): 88-90.

Keehn, Jason; Howell, Eve; Sauer, Mark V. et al. (2015). «How Agencies Market Egg Donation on the Internet: A Qualitative Study». The Journal of Law, Medicine \& Ethics, 43: 610-18.

Klein, Joshua U.; Sauer, Mark V. (2012). «Oocyte Donation», en C. Racowsky; E. Ginsburg (ed.), In Vitro Fertilization: A Comprehensive Guide. Springer: Nueva York, NY.

Klitzman, Robert; Sauer, Mark V. (2015). «Kamakahi vs. ASRM and the Future of Compensation for Human Eggs». Journal of Obstetrics and Gynecology, 213 (2): 186-187.

Konvalinka, Nancy; Hernández Corrochano. Elena (2012). «Methods and Concepts at Work. Generation and Caregiving in «Late-forming Families». Anthropology News, 53(5): 10.

Konvalinka, Nancy (2014). «Timing and Order Conflicts in the Life Course. Schooling, Job Precariousness, and Care-giving in Late-forming Families in Spain», en M. Seifert (ed.), Die mentale Seite der Ökonomie. Gefühl und Empathie im Arbeitsleben. Bausteine aus dem Institut für sächsische Geschichte und Volkskunde. Dresden: Thelem, 31: 221-234.

Kroløkke, Charlotte (2017). «Destination Spain: Negotiating Nationality and Fertility when Traveling for Eggs», en M. Lie and N. Lykke (eds.), Assisted Reproduction Across Borders: Feminist Perspectives on Normalizations, Disruptions and Transmissions. Nueva York, NY : Routledge, Taylor \& Francis Group, 61-71.

Lafuente Funes, Sara (2017). «Bioeconomías reproductivas: los óvulos en la biología pos fecundación in vitro». Tesis Doctoral. Facultad de Ciencias Políticas y Sociología. Universidad Complutense de Madrid.

- (2017). «Egg Donation in the Making: Gender, Selection, and (In)Visibilities in the Spanish Bioeconomy of Reproduction», en V. Pavone. and J. Goven (eds.) Bioeconomies: Life, Technology and Capital in the 21st Century. Palgrave-MacMillan, 253-278. 
Ley 14/2006, de 26 de mayo, sobre técnicas de reproducción humana asistida en España. https://www.boe.es/buscar/act.php?id=BOE-A-2006-9292.

López Gálvez, José Jesús; Moreno García, Juan Manuel (2015). «¿Industria de la fertilidad o respuesta a la búsqueda del hijo biológico?». Boletín del Ministerio de Justicia, Año 69, 2179: 239-265.

Macklon, Nicholas S. (2018). «The Future of IVF». Practical Problems in Assisted Conception: 209.

Marre, Diana; San Roman, Beatriz; Guerra, Diana (2017). «On Reproductive Work in Spain: Transnational Adoption, Egg Donation and Surrogacy». Medical Anthropology, 37 (2): 158-173.

Martin, Lauren Jade (2018). «They Don’t Just Take a Random Egg: Egg Selection in the United States», en A. Wahlberg; T. Gammeltoft (eds), Selective Reproduction in the 21st Century. Palgrave Macmilla (Springer), 151-170.

Mol, Annemarie (2008). The Logic of Care: Health and the Problem of Patient Choice. Londres: Routledge.

Nahavandi, Firouzeh (2016). Commodification of Body Parts in the Global South. Palgrave-MacMillan.

Nahman, Michal (2008). «Romanian Egg Sellers, 'Dignity' and Feminist Alliances in Transnational Ova Exchanges». European Journal of Women's Studies, 15: 2, 2: 65-82

- (2011). «Reverse Traffic: Intersecting Inequalities in Human Egg Donation». Reproductive BioMedicine Online, 23 (5): 626-33.

- (2016). «Romanian IVF: A Brief History Through the Lens of Labour, Migration, and Global Egg Markets». Reproductive BioMedicine Online, 2: 79-87.

Namberger, Verena (2017). «The South African Economy of Egg Donation: Looking at the BioEconomic Side of Normalization», en M. Lie y N. Lykke (eds.), Assisted Reproduction Across Borders: Feminist Perspectives on Normalizations, Disruptions and Transmissions. Nueva York, NY : Routledge, Taylor \& Francis Group, 72-84.

Nygren, Karl; Adamson, David; Zagers-Hochschild, Fernando et al. (2010). «Cross-Border Fertility Care-International Committee Monitoring Assisted Reproductive Technologies Global Survey: 2006 Data and Estimates». Fertility and Sterility, 94 (1): 1-8.

OECD (2017)RealMinimumWages, 2016.https://stats.oecd.org/Index.aspx?DataSetCode=RMW Accessed on July 17, 2017.

Pavone, Vincenzo; Arias, Flor (2012). «Beyond the Geneticization Thesis: The Political Economy of Pgd/Pgs in Spain». Science, Technology \& Human Values 37, 3: 235-61.

Ovulum (2016). https://ovulum.com/infografia-resultados-i-encuesta-internacional-donacionovulos-2016/

Pavone, Vincenzo; Goven. Joana (2017). Bioeconomies: Life, Technology and Capital in the 21st Century. Palgrave-MacMillan.

Pennings, Guido; De Mouzon, J.; Shenfield, F. et al. (2014). «Socio-demographic and fertility-related characteristics and motivations of oocyte donors in eleven European countries». Human Reproduction: 29 (5), 1076-1089.

Perkins, Kiran; Boulet, Sheree L.; Jamieson, Denise J. et al. (2016). «Trends and outcomes of gestational surrogacy in the United States». Fertility and Sterility, 106: 435-42.

Petropanagos, Angel; Cattapan, Alana; Baylis, Françoise et al. (2015) «Social Eggs Freezing: Risk, Benefits and Other Considerations». Canadian Medical Association Journal, 187 (9): 666-669.

Sánchez Molina, Raul (2009). Globalización, migración y maternidad transnacional. Madrid: Ramón Areces. 
Shenfield, F; de Mouzon, J.; Pennings, G.; Feraretti, A.P. et al. (2010). «Cross Border Reproductive Care in Six European Countries». Human Reproduction, 25, 6: 1361-1368.

Scheper-Hughes, Nancy (2003). «Rotten Trade: Millennial Capitalism, Human Values and Global Justice in Organs Trafficking». Journal of Human Rights, 2 (2): 197-226

- (2007). «The Tyranny of the Gift: Sacrificial Violence in Living Donor Transplants». American Journal of Transplantation, 7(3): 507-511.

Scheper-Hughes, Nancy; Wacquant, Loïc (eds.) (2002). Commodifying Bodies. Londres: Sage Press.

Scherman, Rhoda; Misca, Gabriela; Rotabi, Karen et al. (2016). «Global commercial surrogacy and international adoption: parallels and differences». Adoption \& Fostering, 40: 20-35.

Schurr, Carolin (2018). «The baby business booms: Economic geographies of assisted reproduction». Geography Compass, 12 (8): 1-15.

SEF (2009). «Informe Estadístico de Técnicas de Reproducción Asistida.» 49. Madrid: Sociedad Española de Fertilidad.

- (2015). «Informe Estadístico de Técnicas de Reproducción Asistida.» 49. Madrid: Sociedad Española de Fertilidad.

Speier, Amy (2016). Fertility Holidays: IVF Tourism and the Reproduction of Whiteness. Nueva York: Nueva York University Press

Titmuss, Richard (1997). The Gift Relationship. Revised edition (Ann Oakley and John Ashton, eds). Nueva York: The New Press.

Tober, Diane (2002). «Semen as Gift, Semen as Goods: Reproductive Workers and the Market in Altruism», en N. Scheper-Hughes y L. Wacquant (eds.) Commodifying Bodies. Londres: Sage Press, 137-160.

- (2018). Romancing the Sperm: Shifting Biopolitics and the Making of Modern Families. Rutgers University Press.

Tober, Diane; Nahman, Michal (eds.) (2019). «Beyond Bioavailable Bodies: Reproductive Work and Cross-Border Family Making». Special edition of Body and Society, Sage Press (en prensa).

Tober, Diane; Kroløkke, Charlotte (2019). «'Working Vacation’: Traveling Donors and the Reproductive Workforce in the Global Human Egg Trade». Special edition of Body and Society, Sage Press (en prensa).

Vlasenko, Polina (2015). «Desirable Bodies/Precarious Laborers: Ukrainian Egg Donors in Context of Transnational Fertility». en V. Kantsa, G. Zanini, L. Papadopoulou (eds.), (In) Fertile Citizens. Anthropological and Legal Challenges of Assisted Reproduction Technologies. (IN) FERCIT: Univesity of the Aegean, 197-216.

- (2016). «From Precarity to Self-Governance» en M. Lie and N. Lykke (eds.) Assisted Reproduction Across Borders: Feminist Perspectives on Normalizations, Disruptions and Transmissions. Nueva York, NY : Routledge, Taylor \& Francis Group, 219-231.

Waldby, Catherine (2006). «Feminist Technoscience: Intimacy, Embodiment and Abjection in Sciences Studies». Science Studies, 19 (2): 3-5.

- (2015). «The oocyte market and social egg freezing: From scarcity to singularity». Journal of Cultural Economy, 8: 275-91.

Waldby, Catherine; Mitchell, Robert (2006). Tissues Economies: Blood, Organs, Cell Lines in Late Capitalism. Durham: Duke University Press.

Waldby, Catherine; Cooper, Melinda (2008). «The Biopolitics of Reproduction: Post-Fordist Biotechnology and Women's Clinical Labour». Australian Feminist Studies, 23 (55): 57-73. 
Waldby, Catherine; Kerridge, Ina; Boulos, Margaret et al. (2013). «From Altruism to Monetisation: Australian Women's Ideas About Money, Ethics and Research Eggs». Social Science and Medicine, 94: 34-42.

Whittaker, Andrea (2015). «Technology, Biopolitics, Rationalities and Choices: Recent Studies of Reproduction». Medical Anthropology, 34 (3): 259-73.

Whittaker, Andrea; Speier, Amy (2010). «Cycling Overseas»: Care, Commodification and Stratification in Cross-Border Reproductive Travel». Medical Anthropology, 29(4): 363-83. 